\title{
High red blood cell distribution width is closely associated with in-stent restenosis in patients with unstable angina pectoris
}

\author{
Ning Geng ${ }^{1 *} \mathbb{D}$, Guangsheng Su', Shaojun Wang ${ }^{1}$, Deling Zou', Wenyue Pang ${ }^{1}$ and Yingxian Sun ${ }^{2}$
}

\begin{abstract}
Background: In-stent restenosis remains an unresolved issue. Inflammation plays a pivotal role in the process of in-stent restenosis. Significant and positive associations were found between red blood cell distribution width (RDW) and inflammation. But whether there is a close relationship between higher RDW and in-stent restenosis is still not clarified.

Methods: This retrospective observational study investigated 214 consecutive patients with unstable angina pectoris who underwent successful percutaneous coronary interventions with drug-eluting stents. Patients were divided into three groups according to baseline RDW before percutaneous coronary interventions (low RDW group: $\leq 12.5 \%$; intermediate RDW group:> 12.5\% and $\leq 13.5 \%$; high RDW group:> 13.5\%). The follow-up angiographies were routinely performed $9-12$ months after the initial percutaneous coronary interventions. The multivariate logistic regression analysis was employed to determine the independent predictors of in-stent restenosis.
\end{abstract}

Results: The in-stent restenosis rate was significantly higher in group with higher baseline RDW value (12.3, 19.7, $47.7 \%$ in low, intermediate, and high RDW groups respectively, $P<0.001$ ). The baseline RDWs were significantly higher in patients with in-stent restenosis compared with those in patients without in-stent restenosis $(13.7 \pm 0.8 \%$ vs. $13.0 \pm 0.8 \%, P<0.001)$. For prediction of in-stent restenosis, the ROC (receiver operating characteristic) curve analysis demonstrated the optimal RDW cutoff value was 13.37 (sensitivity: 65.5\%, specificity: 73.6\%); the diagnosis cutoff value was 13.89 (sensitivity: 40.0\%, specificity: $91.8 \%$ ); the screening cutoff value was 12.99 (sensitivity: 83.6\%, specificity: 49.1\%). By multivariate logistic analysis, higher baseline RDW (odds ratio [OR], 5.179; 95\% confidence interval [CI], 2.568 to 10.446; $P<0.001$ ) together with lower baseline indirect bilirubin $(\mathrm{OR}, 0.413 ; 95 \% \mathrm{Cl}, 0.305$ to $0.559 ; P<0.001)$ and diabetes $(\mathrm{OR}, 4.077 ; 95 \% \mathrm{Cl}$, 1.654 to $10.054 ; P=0.002$ ) were closely associated with in-stent restenosis at followup (11.1 \pm 5.8 months).

Conclusions: The baseline RDW was closely associated with in-stent restenosis at follow-up. The patients with higher baseline RDW might have more chances to develop in-stent restenosis at followup.

Keywords: Unstable angina pectoris, in-stent restenosis, Percutaneous coronary intervention, Angiography, Red blood cell distribution width

\footnotetext{
* Correspondence: ninggeng@aliyun.com

${ }^{1}$ Department of Cardiology, Shengjing Hospital of China Medical University,

No.36, Sanhao Street, Heping District, Shenyang City, Liaoning Province,

People's Republic of China

Full list of author information is available at the end of the article
}

(C) The Author(s). 2019 Open Access This article is distributed under the terms of the Creative Commons Attribution 4.0 International License (http://creativecommons.org/licenses/by/4.0/), which permits unrestricted use, distribution, and

reproduction in any medium, provided you give appropriate credit to the original author(s) and the source, provide a link to the Creative Commons license, and indicate if changes were made. The Creative Commons Public Domain Dedication waiver (http://creativecommons.org/publicdomain/zero/1.0/) applies to the data made available in this article, unless otherwise stated. 


\section{Background}

Percutaneous coronary intervention (PCI) has become a promised therapy modality for coronary artery disease since 1979 [1], and drug-eluting stents (DES) have shown to significantly reduce the rate of in-stent restenosis (ISR) [2]. However, ISR has been encountered as a major limitation to the long-term efficacy of PCI even in the era of DES. In a meta-analysis of randomized controlled trials [3], the overall adjusted rate for angiographic restenosis was $10.5 \%$ in the DES group versus $31.7 \%$ in the control group $(P<0.001)$.

Although not completely elucidated, the inflammation is believed to play a critical role in the process of ISR [4]. The pathophysiology of ISR, which is characterized by neo-intimal hyperplasia, is an overreaction of the woundhealing response after the vascular injury caused by balloon dilation (barotrauma) and stent placement during PCI [5]. Vascular mechanical injury caused by PCI leads to substantial inflammation reaction which stimulates vascular smooth muscle cell proliferation and extracellular matrix deposition, resulting in neo-intimal thickening and restenosis [4]. Pre-interventional inflammatory status correlates with post-interventional adverse outcomes. Walter et al. found that higher tertiles of preprocedural C-type creative protein levels were independently associated with a higher risk of major adverse clinical events and angiographic restenoses after stenting [6].

The red blood cell distribution width (RDW) is a measurement of the size variation as well as an index of the heterogeneity of the erythrocytes. An increased RDW has been reported to be associated with increased inflammation status [7]. Higher RDW has been reported to be closely associated with adverse outcomes of cardiovascular disease such as heart failure [8] and prior myocardial infarction [9]. In this study, we explored whether the RDW before PCI was associated with ISR and could be used as an independent predictor of ISR after PCI in patients with unstable angina pectoris.

\section{Methods}

\section{Patients and study design}

This was a retrospective observational cohort study carried out at Shengjing hospital of China medical university. The consecutive unstable angina pectoris patients with coronary second generation, sirolimus eluting stent implantations and planned follow-up angiographies in our hospital from March 2015 to September 2015 were studied. All patient's data were de-identified prior to data collection and the need for ethics approval was waived by our hospital. We excluded the patients with failed stenting; acute myocardial infarction; stable angina pectoris; major adverse cardiac events (death, myocardial infarction, stroke, coronary artery bypass graft, repeated PCI) after PCI; and patients with other conditions that can cause increased RDW (for example: anemia, heart failure, current acute infection, malignancy, chronic inflammatory disease and autoimmune disease) before the procedure and during the follow-up. The initial assessments of the patients included a medical history, physical examination, blood biochemistry tests for a complete blood cell count; total cholesterol, low-density lipoprotein cholesterol, high-density lipoprotein cholesterol and triglycerides; blood urea nitrogen; serum creatinine; nitrogen terminal-pro brain natriuretic peptide. The blood samples were drawn from participating patients after an overnight fast of more than $12 \mathrm{~h}$ in the morning of the initial PCI and were tested at the center for clinical chemistry of our hospital. The levels of RDW were measured with the use of the BECKMAN Ac. T 5 diff as a continuous variable. The normal range of RDW is 10.0-15.0 in our hospital.

\section{$\mathrm{PCl}$ procedures and follow-up angiography evaluations}

Drug eluting stents were implanted in all patients according to the current guidelines. All patients received antiplatelet therapy before and after the procedures: 100 $\mathrm{mg}$ aspirin was continued indefinitely and $75 \mathrm{mg}$ clopidogrel was continued for at least 1 year after stent implantation. The follow-up angiographies were routinely performed 9-12 months after the initial PCIs. The evaluations of restenosis were carried out using the conventional QCA technique. ISR at follow-up was defined as luminal narrowing of more than $50 \%$ occurring in the segment within the stent or within a $5 \mathrm{~mm}$ segment proximal or distal to the stent.

\section{Statistical analysis}

IBM SPSS Statistics 23.0 was used to analyze the data. Categorical variables were reported as frequencies (percentage) and were compared using chi-square analysis. Continuous variables were reported as means \pm standard deviations and were compared by Student's $t$ test. A one-way analysis of variance was used to determine differences among different categories of RDW. Differences at a two tailed $P$ value less than 0.05 were considered significant. Binary logistic regression analysis was carried out to assess the risk factors of ISR. Odds ratio (OR) and 95\% confidence interval (CI) were calculated. Among the variables tested, only those variables with statistical significance set at $P$ less than 0.05 at univariate analysis together with age and gender were included in a multivariate logistic regression model to determine the independent predictors of ISR. We also performed a receiver operating characteristics (ROC) curve analysis to determine the optimal cutoff, diagnostic cutoff, screening cutoff value of RDW for prediction of in-stent restenosis. The optimal cut-off value is the point on the curve that is closest to the top of the left hand $y$-axis. This is the point at which the true positive rate is optimized and 
the false positive rate is minimized. The screening cutoff value is chosen to maximize the sensitivity of the test while maintaining an appropriate speciality. The diagnostic cut-off value is chosen to maximize the specificity of the test while maintaining an appropriate sensitivity. The determinations of diagnostic cutoff and screening cutoff value are often an expert decision and subjective to some degree.

\section{Results}

General characteristics of the patients with in-stent restenosis and without in-stent restenosis

A total of 233 patients with unstable angina pectoris and drug eluting stent implantations were screened. Eleven patients lost follow-up; 2 patients died; 6 patients suffered heart failure during follow-up. So 214 patients were eligible for this study. After an average follow-up of $11.1 \pm 5.8$ months, 55 patients suffered in-stent restenosis. The baseline characteristics of these patients were summarized in Table 1. There were no differences in the follow-up period between the ISR group and non-ISR group. Diabetes were more common in patients with ISR. Patients with ISR were more likely to be older; had a higher baseline and followup RDW; and lower total bilirubin, direct and indirect bilirubin; had longer stents of smaller diameters implanted.

\section{Comparison between the baseline RDWs and the follow- up RDWs}

We compared the RDWs prior to the PCI (RDW baseline) with the RDWs at follow-up ( $\left.\mathrm{RDW}_{\text {follow-up }}\right)$ and interestingly we found that the RDWs increased significantly during follow-up in both the non-ISR group $(13.0 \pm 0.8$ vs. $13.2 \pm 0.8 ; P=0.003)$ and the ISR group (13.7 \pm 0.8 vs. $14.0 \pm 1.4 p=0.022)$. The increases of RDW during follow-up were not significantly different between in nonISR and ISR groups $(P=0.472)$. (Table 2$)$.

\section{Relationship between baseline RDW and the occurrence of ISR at follow-up}

We divided the participants into three groups according to the tertile of RDW values before the initial PCI (low RDW group: $\leq 12.5 \%$; intermediate RDW group: $>12.5 \%$ and $\leq 13.5 \%$; high RDW group: $>13.5 \%$ ) to explore the relationship between the baseline RDWs and the ISR at follow-up. The clinical and angiographic characteristics were compared among different RDW groups (Table 3). We found that the patients with higher baseline RDWs were more likely to develop ISR at follow-up (low RDW: 12.3\%; intermediate RDW:19.7\%; high RDW:47.7\%; $P<$ $0.001)$. There were no statistically significant differences in clinical and laboratory characteristics among different RDW categories except age, stent diameter and hemoglobin.

\section{Predictors of ISR at follow-up}

Binary logistic regression analysis was used to assess independent predictors of ISR at follow-up. All variables that were clinically important and potentially correlated with ISR were included in the univariate logistic model (Table 4). We found that diabetes, indirect bilirubin, baseline RDW, hemoglobin were the significant univariable predictors of the ISR. Then we applied multivariate logistic regression analysis that included all the significant univariable predictors found in Table 4 to determine the independent predictors of ISR. The odds ratio and $P$ value were adjusted for age and gender (Table 5). In the multivariate analysis model, only the baseline RDW (OR, 5.179; 95\% CI, 2.568 to 10.446, $P<0.001$ ); indirect bilirubin (OR, $0.413 ; 95 \% \mathrm{CI}, 0.305$ to $0.559, P<$ 0.001 ) and diabetes (OR, 4.077; 95\% CI, 1.654 to 10.054, $P=0.002)$ were significant independent predictors of ISR at follow-up.

\section{ROC curve analysis}

ROC curve analysis of the diagnostic accuracy of the RDW for in-stent restenosis showed an area under the curve (AUC) of 0.743 (95\% CI, 0.664 to $0.822 ; P<0.001$ ) (Fig. 1), and the optimal cutoff value of RDW for discrimination of in-stent restenosis was 13.37 (sensitivity: $65.5 \%$, specificity:73.6\%). The diagnostic cutoff value of RDW was 13.89 with a specificity $91.8 \%$ and sensitivity $40 \%$. A RDW 12.99 was used for the screening cutoff value with a sensitivity $83.6 \%$ and specificity $49.1 \%$.

\section{Discussion}

In the present study, we found that the baseline RDW, indirect bilirubin and diabetes before PCI were strongly associated with the occurrence of ISR and might be used as independent predictors of ISR in patients with unstable angina pectoris at followup. The RDW is a measurement of the size variation as well as an index of the heterogeneity of the erythrocytes. Both the red blood cell destruction and decreased production can increase the value of RDW. So the RDW can be typically used in the differential diagnosis of underlying anemias [10]. However, several lines of evidences have recently attested the pathogenetic link between RDW and a lot of cardiovascular disorders. The increased RDW can serve as an independent predictor of mortality in patients with heart failure [8], coronary heart disease [9], and even in unselected general middle-aged and older adults [11].

In our study, we tried to evaluate the relationship between the higher RDW before PCI and the risk of ISR at follow-up. Although the exact pathophysiological mechanisms underlying the association between increased RDW and ISR are not fully understood, we believe that the inflammatory status, which can both alter erythrocyte homeostasis and affect the process of ISR, are likely 
Table 1 Baseline characteristics of the patients included

\begin{tabular}{|c|c|c|c|c|}
\hline Variable & Overall $(n=214)$ & Non-ISR $(n=159)$ & $\operatorname{ISR}(n=55)$ & $P$ value \\
\hline Age (years) & $63.3 \pm 9.9$ & $62.9 \pm 9.7$ & $64.4 \pm 10.2$ & 0.040 \\
\hline Male gender (\%) & $151(70.1)$ & $112(70.4)$ & 39 (70.9) & 0.948 \\
\hline Follow-up period (months) & $11.1 \pm 5.8$ & $10.8 \pm 5.4$ & $12.1 \pm 7.1$ & 0.164 \\
\hline Length of stents (mm) & $26.8 \pm 5.6$ & $26.4 \pm 6.0$ & $28.0 \pm 4.3$ & 0.034 \\
\hline Diameter of stents (mm) & $3.1 \pm 0.4$ & $3.1 \pm 0.4$ & $2.9 \pm 0.3$ & 0.014 \\
\hline Complex lesion ${ }^{\mathrm{a}}(\%)$ & $91(42.5)$ & $65(40.9)$ & $26(47.2)$ & 0.408 \\
\hline \multicolumn{5}{|l|}{ Clinical variables } \\
\hline Hypertension (\%) & $134(62.6)$ & $98(61.6)$ & $36(65.5)$ & 0.614 \\
\hline Diabetes mellitus (\%) & $68(31.8)$ & $37(23.3)$ & $31(56.4)$ & $<0.001$ \\
\hline \multicolumn{5}{|l|}{ Laboratory results } \\
\hline Total bilirubin $(\mu \mathrm{mol} / \mathrm{L})$ & $12.4 \pm 4.5$ & $13.6 \pm 4.4$ & $8.9 \pm 2.8$ & $<0.001$ \\
\hline Direct bilirubin $(\mu \mathrm{mol} / \mathrm{L})$ & $4.5 \pm 1.8$ & $4.9 \pm 1.8$ & $3.4 \pm 1.3$ & $<0.001$ \\
\hline Indirect bilirubin $(\mu \mathrm{mol} / \mathrm{L})$ & $7.9 \pm 2.9$ & $8.7 \pm 2.8$ & $5.5 \pm 1.7$ & $<0.001$ \\
\hline Baseline RDW (\%) & $13.1 \pm 0.8$ & $13.0 \pm 0.8$ & $13.7 \pm 0.8$ & $<0.001$ \\
\hline RDW (\%) at followup & $13.4 \pm 1.0$ & $13.2 \pm 0.8$ & $14.0 \pm 1.4$ & $<0.001$ \\
\hline $\mathrm{Hb}(\mathrm{g} / \mathrm{L})$ & $137.3 \pm 15.0$ & $138.0 \pm 14.6$ & $135.4 \pm 16.3$ & 0.270 \\
\hline Baseline WBC $\left(10^{9} / \mathrm{L}\right)$ & $7.7 \pm 2.7$ & $7.9 \pm 2.8$ & $7.3 \pm 2.5$ & 0.553 \\
\hline WBC at followup $\left(10^{9} / \mathrm{L}\right)$ & $6.8 \pm 1.8$ & $6.7 \pm 1.7$ & $7.0 \pm 2.0$ & 0.267 \\
\hline BUN (mmol/L) & $6.0 \pm 2.0$ & $5.9 \pm 1.9$ & $6.3 \pm 2.2$ & 0.322 \\
\hline eGFR (ml/min) & $84.6 \pm 23.6$ & $84.5 \pm 22.8$ & $85.2 \pm 26.1$ & 0.849 \\
\hline $\mathrm{TG}(\mathrm{mmol} / \mathrm{L})$ & $1.5(1.2)^{*}$ & $1.6(1.2)^{*}$ & $1.4(1.3)^{*}$ & 0.476 \\
\hline $\mathrm{HDL}-\mathrm{C}(\mathrm{mmol} / \mathrm{L})$ & $1.0 \pm 0.3$ & $1.0 \pm 0.3$ & $1.0 \pm 0.3$ & 0.553 \\
\hline LDL-C (mmol/L) & $2.7 \pm 1.0$ & $2.7 \pm 0.9$ & $2.7 \pm 1.2$ & 0.867 \\
\hline \multicolumn{5}{|l|}{ Pharmacotherapy } \\
\hline ACEl or ARB & $142(66.4)$ & $108(67.8)$ & $34(62.1)$ & 0.570 \\
\hline B-Blocker & $70(32.6)$ & $51(32.2)$ & $19(34.5)$ & 0.819 \\
\hline Statin & $186(87.1)$ & 139 (87.4) & 47 (86.2) & 0.873 \\
\hline
\end{tabular}

Data are represented as number (\%) or mean \pm standard deviation

${ }^{a}$ Complex lesion refers to type B2 and $C$ lesion

*: median (inter-quartile range)

$A C E I$ Angiotensin-converting enzyme inhibitor, $A R B$ Angiotensin receptor blocker, $B U N$ Blood urea nitrogen, eGFR estimated glomerular filtration rate, $H b$ Hemoglobin, HDL-C High-density lipoprotein cholesterol, ISR In-stent restenosis, LDL-C Low-density lipoprotein cholesterol, RDW Red blood cell distribution width, TG Triglyceride, WBC White blood cell

to play an important role in the association between the baseline RDW and ISR at follow-up. The RDW can act as a marker of the inflammatory state in the body. In a series of clinical investigations, significant and positive associations were found between RDW and a variety of inflammatory markers, such as high sensitive C-creative protein and erythrocyte sedimentation rate [7], interleukin
(IL)-6 [12], soluble transferrin receptor, soluble tumor necrosis factor (TNF) receptor I, soluble TNF receptor II [13]. Inflammation can contribute to an increased RDW by impairing iron metabolism, inhibiting the production of or response to erythropoietin, or by shortening red blood cell survival [14] and it has been demonstrated that inflammatory cytokines, such as TNF- $\alpha$, IL-1ß口and IL-6,

Table 2 Comparison between the baseline RDW and the follow-up RDW

\begin{tabular}{lllll}
\hline & RDW baseline $($ Mean \pm SD) & RDW followup $($ Mean \pm SD) & RDW change (Mean \pm SD) & $P$ value \\
\hline Overall (\%) & $13.1 \pm 0.8$ & $13.4 \pm 1.0$ & $0.2 \pm 0.8$ & $<0.001$ \\
Non-ISR (\%) & $13.0 \pm 0.8$ & $13.2 \pm 0.8$ & $0.2 \pm 0.8^{\text {a }}$ & 0.003 \\
ISR (\%) & $13.7 \pm 0.8$ & $14.0 \pm 1.4$ & $0.3 \pm 0.9^{\text {a }}$ & 0.022 \\
\hline
\end{tabular}

aThe difference of RDW changes between in Non-ISR and ISR groups is not statistically significant $(P=0.472)$ 
Table 3 Clinical characteristics of different red blood cell distribution width categories

\begin{tabular}{|c|c|c|c|c|}
\hline & Low RDW $(n=73)$ & Intermediate RDW $(n=76)$ & High RDW $(n=65)$ & $P$ value \\
\hline RDW (\%) & $12.3 \pm 0.6$ & $13.2 \pm 0.2$ & $14.1 \pm 0.5$ & $<0.001$ \\
\hline Age (years) & $64.2 \pm 8.7$ & $61.0 \pm 10.7$ & $64.9 \pm 9.8$ & 0.038 \\
\hline Fellow-up (month) & $11.0 \pm 7.0$ & $11.1 \pm 4.1$ & $11.4 \pm 6.2$ & 0.931 \\
\hline Male gender & $55(75.3)$ & $53(69.7)$ & $43(66.2)$ & 0.488 \\
\hline ISR (\%) & $9(12.3)$ & $15(19.7)$ & $31(47.7)$ & $<0.001$ \\
\hline Stent diameter (mm) & $3.1 \pm 0.2$ & $3.1 \pm 0.4$ & $2.9 \pm 0,3$ & 0.028 \\
\hline Stent length (mm) & $26.2 \pm 6.0$ & $27.3 \pm 5.3$ & $27.0 \pm 5.6$ & 0.510 \\
\hline Complex lesion ${ }^{\mathrm{a}}(\%)$ & $31(42.5)$ & $29(38.2)$ & $31(47.7)$ & 0.521 \\
\hline \multicolumn{5}{|l|}{ Clinical variables } \\
\hline Hypertension & $46(63.0)$ & $58(76.3)$ & $38(58.5)$ & 0.132 \\
\hline Diabetes mellitus & $17(25.0)$ & $27(39.7)$ & $24(35.3)$ & 0.156 \\
\hline \multicolumn{5}{|l|}{ Laboratory results } \\
\hline Total bilirubin ( $\mu \mathrm{mol} / \mathrm{L})$ & $12.4 \pm 4.4$ & $12.8 \pm 4.7$ & $12.0 \pm 4.6$ & 0.584 \\
\hline Direct bilirubin ( $\mu \mathrm{mol} / \mathrm{L})$ & $4.4 \pm 1.7$ & $4.6 \pm 2.0$ & $4.6 \pm 1.9$ & 0.586 \\
\hline Indirect bilirubin ( $\mu \mathrm{mol} / \mathrm{L})$ & $7.9 \pm 2.9$ & $8.2 \pm 2.9$ & $7.3 \pm 3.0$ & 0.200 \\
\hline $\mathrm{Hb}(\mathrm{g} / \mathrm{L})$ & $138.3 \pm 14.1$ & $140.9 \pm 14.3$ & $132.0 \pm 15.6$ & 0.002 \\
\hline WBC $\left(10^{9} / L\right)$ & $7.7 \pm 2.5$ & $7.9 \pm 3.1$ & $7.6 \pm 2.5$ & 0.751 \\
\hline BUN (mmol/L) & $5.9 \pm 1.8$ & $5.8 \pm 1.8$ & $6.3 \pm 2.5$ & 0.350 \\
\hline eGFR (ml/min) & $85.6 \pm 23.0$ & $86.5 \pm 23.6$ & $81.4 \pm 24.2$ & 0.397 \\
\hline $\mathrm{TG}(\mathrm{mmol} / \mathrm{L})$ & $2.0 \pm 1.3$ & $1.9 \pm 1.1$ & $2.0 \pm 2.1$ & 0.963 \\
\hline $\mathrm{HDL}-\mathrm{C}(\mathrm{mmol} / \mathrm{L})$ & $1.0 \pm 0.2$ & $1.0 \pm 0.3$ & $1.1 \pm 0.3$ & 0.257 \\
\hline LDL-C (mmol/L) & $2.6 \pm 0.8$ & $2.8 \pm 0.8$ & $2.7 \pm 1.2$ & 0.524 \\
\hline \multicolumn{5}{|l|}{ Pharmacotherapy } \\
\hline ACEl or ARB & $50(68.5)$ & $52(68.4)$ & $40(61.5)$ & 0.616 \\
\hline$\beta$-Blocker & $23(31.5)$ & 25 (32.9) & $21(32.3)$ & 0.984 \\
\hline Statin & $63(86.3)$ & $68(89.5)$ & $54(83.1)$ & 0.542 \\
\hline
\end{tabular}

Patients were divided into three groups according to baseline RDW (low: $\leq 12.5 \%$; intermediate:> 12.5\% and $\leq 13.5 \%$; high:> 13.5\%)

Data are represented as number (\%) or mean \pm SD

a: refers to type $B_{2}$ and $C$ lesions

$A C E I$ Angiotensin-converting enzyme inhibitor, ARB Angiotensin receptor blocker, BUN Blood urea nitrogen, eGFR estimated glomerular filtration rate, $H b$ Hemoglobin, HDL-C High-density lipoprotein cholesterol, ISR In-stent restenosis, LDL-C Low-density lipoprotein cholesterol, RDW Red blood cell distribution width, TG Triglyceride, WBC White blood cell

can desensitize bone marrow erythroid progenitors to erythropoiesis, inhibit red blood cell maturation and thereby promote anisocytosis $[15,16]$.

Though the causative mechanisms of ISR have not yet been fully elucidated, the inflammation is believed to play a pivotal role in the development of ISR. The vascular injuries caused by PCI can up-regulate inflammatory responses and measurements of several factors in blood samples. According to Hojo Y et al., IL-6 concentrations in coronary sinus blood increased immediately after PCI, and there was a positive correlation between increased IL-6 concentrations immediately after PCI and restenoses 6 months after PCI [17].

In our study, the RDW as a marker of inflammatory status was found to increase significantly during followup in both ISR and non-ISR groups (Table 2), which was consistent with the up-regulated inflammatory status caused by PCI.

The inflammatory responses to the endothelial denudation and subintimal hemorrhage caused by PCI result in several proliferative processes, including vascular smooth muscle cells proliferation and migration, extracellular matrix formation, and neo-intimal hyperplasia, which are the major pathophysiological mechanisms of ISR [18, 19]. Some physiological or pathophysiological reactions (such as activation of platelets and related growth factors, pro-inflammatory cytokines, leukocytes, and the coagulation-fibrinolysis system, as well as events at the platelet surface) set this proliferative process into motion [20]. Although the inflammatory reactions caused by PCI can be physiological, in some patients the inflammatory reactions may over-response 
Table 4 Univariable logistic regression analysis for the prediction of ISR at followup

\begin{tabular}{|c|c|c|c|}
\hline Variables & OR & $95 \% \mathrm{Cl}$ & $P$ value \\
\hline Age & 1.008 & $0.941-1.079$ & 0.817 \\
\hline Gender & 0.620 & $0.163-2.356$ & 0.483 \\
\hline Hypertension & 1.781 & $0.542-5.853$ & 0.342 \\
\hline Diabetes mellitus & 3.583 & $1.122-11.441$ & 0.031 \\
\hline LDL-C & 0.738 & $0.384-1.419$ & 0.363 \\
\hline $\mathrm{HDL}-\mathrm{C}$ & 0.879 & $0.090-8.625$ & 0.912 \\
\hline TG & 0.873 & $0.554-1.376$ & 0.558 \\
\hline BUN & 1.071 & $0.802-1.432$ & 0.641 \\
\hline eGFR & 1.006 & $0.975-1.037$ & 0.724 \\
\hline Indirect bilirubin & 0.363 & $0.220-0.599$ & $<0.001$ \\
\hline Direct bilirubin & 1.004 & $0.549-1.836$ & 0.988 \\
\hline Baseline RDW & 3.903 & $1.375-11.075$ & 0.011 \\
\hline Follow-up RDW & 1.727 & $0.745-4.007$ & 0.203 \\
\hline $\mathrm{Hb}$ & 1.041 & $1.000-1.083$ & 0.048 \\
\hline Baseline WBC & 0.764 & $0.574-1.018$ & 0.066 \\
\hline Followup WBC & 1.322 & $0.920-1.901$ & 0.131 \\
\hline Complex lesion $^{\mathrm{a}}$ & 1.142 & $0.346-3.764$ & 0.828 \\
\hline Stent diameter (mm) & 0.427 & $0.089-2.034$ & 0.285 \\
\hline Stent length (mm) & 1.075 & $0.965-1.197$ & 0.191 \\
\hline ACEI or ARB & 0.425 & $0.126-1.432$ & 0.167 \\
\hline$\beta$-blocker & 2.525 & $0.731-8.716$ & 0.143 \\
\hline Statin & 0.818 & $0.191-3.492$ & 0.786 \\
\hline
\end{tabular}

${ }^{\mathrm{a}}$ Complex lesion refers to type $\mathrm{B} 2$ and $\mathrm{C}$ lesion

$A C E I$ Angiotensin-converting enzyme inhibitor, $A R B$ Angiotensin receptor blocker, $B U N$ Blood urea nitrogen, eGFR estimated glomerular filtration rate, $\mathrm{Hb}$ Hemoglobin, HDL-C High-density lipoprotein cholesterol, ISR In-stent restenosis, $L D L-C$ Low-density lipoprotein cholesterol, $R D W$ Red blood cell distribution width, TG Triglycerides, WBC White blood cell

resulting in an overshot proliferative process which can cause ISR of the treated vessels. In our study, the patients with ISR had higher baseline RDWs and follow-up RDWs than the patients without ISR (Table 1), which suggests the patients with ISR may be in a higher level of inflammatory status and have a greater inflammatory response to PCI than those without ISR.

Table $\mathbf{5}$ Independent predictors of ISR at followup by multivariable logistic regression analysis

\begin{tabular}{llll}
\hline Variables & OR & $95 \% \mathrm{Cl}$ & $P$ value \\
\hline Age & 1.035 & $0.987-1.085$ & 0.151 \\
Gender & 0.615 & $0.210-1.802$ & 0.376 \\
Baseline RDW & 5.179 & $2.568-10.446$ & $<0.001$ \\
$\mathrm{Hb}$ & 1.029 & $0.995-1.064$ & 0.093 \\
Indirect bilirubin & 0.413 & $0.305-0.559$ & $<0.001$ \\
DM & 4.077 & $1.654-10.054$ & 0.002 \\
\hline
\end{tabular}

Cl Confidence interval, $\mathrm{Hb}$ Hemoglobin, ISR In-stent restenosis, OR Odds ratio, $R D W$ Red blood cell distribution width

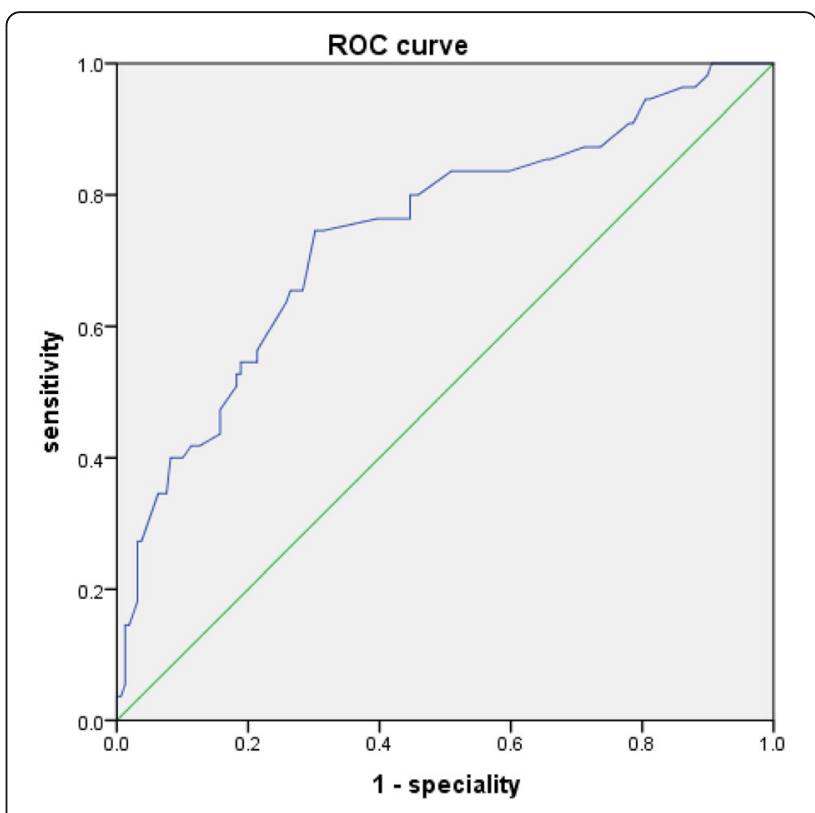

Fig. 1 The ROC curve analysis of RDW for predicting ISR. ISR, in-stent restenosis; RDW, red blood cell distribution width; ROC, receiver operating characteristic

Kuwano T. et al. [21], demonstrated that the baseline serum bilirubin, as an antioxidant agent, could act as an independent predictor of coronary ISR. In our study, both indirect and direct bilirubin were significantly lower in patients who developed ISR (Table 1). We found that only the baseline serum indirect bilirubin was strongly associated with coronary ISR at follow-up and might be an independent predictor of coronary ISR by multivariate logistic regression analysis (Table 5).

\section{Limitations}

In the present study, there were some limitations. First, the sample size was relatively small and study design was retrospective. Large prospective trials are needed to confirm whether RDW can act as a clinical independent predictor of ISR. Second, the late catch-up phenomenon of restenosis especially for DESs beyond 1 year after initial PCI has been recognized [22]. The follow-up periods of $11.1 \pm 5.8$ months were relatively short and studies with long-term follow-up are required.

\section{Conclusions}

The baseline RDW was closely associated with in-stent restenosis at follow-up. The patients with higher baseline RDWs together with lower indirect bilirubin and diabetes had a higher risk of suffering ISR. These findings have important clinical implications. Special attentions should be paid to the patients with higher RDWs before PCI who may have more chances to develop ISR in the future. 


\section{Abbreviations}

DES: Drug-eluting stents; IL: Interleukin; ISR: In-stent restenosis; PCI: Percutaneous coronary intervention; RDW: Red blood cell distribution width; ROC: Receiver operating characteristics; TNF: Tumor necrosis factor

\section{Acknowledgements}

Not applicable.

\section{Authors' contributions}

NG and YXS conceived the study design. DLZ and PYW developed the methods and performed statistics. NG, GSS and SJW drafted the manuscript. All authors read and approved the final manuscript.

\section{Funding}

None declared.

\section{Availability of data and materials}

The data and material that support the findings of this study are available in the hospital information system (HIS) of our hospital.

\section{Ethics approval and consent to participate}

All patient's data were de-identified prior to data collection and the need for ethics approval was waived by our hospital for no patient's individual information being revealed and no additional interventions being administrated.

\section{Consent for publication}

Not applicable.

\section{Competing interests}

The authors declare that they have no competing interests.

\section{Author details}

'Department of Cardiology, Shengjing Hospital of China Medical University, No.36, Sanhao Street, Heping District, Shenyang City, Liaoning Province, People's Republic of China. ${ }^{2}$ Department of Cardiology, The First Affiliated Hospital of China Medical University, Shenyang City, Liaoning Province, China.

Received: 23 January 2019 Accepted: 15 July 2019

Published online: 24 July 2019

\section{References}

1. Gruntzig AR, Senning A, Siegenthaler WE. Nonoperative dilatation of coronary-artery stenosis: percutaneous transluminal coronary angioplasty. N Engl J Med. 1979;301:61-8.

2. Moses JW, Leon MB, Popma JJ, Fitzgerald PJ, Holmes DR, O'Shaughnessy C, et al. Sirolimus-eluting stents versus standard stents in patients with stenosis in a native coronary artery. N Engl J Med. 2003;349:1315-23.

3. Roiron C, Sanchez P, Bouzamondo A, Lechat P, Montalescot G. Drug-eluting stents: an updated meta-analysis of randomised controlled trials. Heart. 2006;92:641-9.

4. Welt FG, Rogers C. Inflammation and restenosis in the stent era. Arterioscler Thromb Vasc Biol. 2002;22:1769-76.

5. Hoffmann R, Mintz GS, Dussaillant GR, Popma JJ, Pichard AD, Satler LF, et al. Patterns and mechanisms of in-stent restenosis. A serial intravascular ultrasound study. Circulation. 1996;94:1247-54.

6. Walter DH, Fichtlscherer S, Sellwig M, Auch-Schwelk W, Schächinger V, Zeiher AM. A preprocedural C-reactive protein levels and cardiovascular events after coronary stent implantation. J Am Coll Cardiol. 2001;37:839-46.

7. Lippi G, Targher G, Montagnana M, Salvagno GL, Zoppini G, Guidi GC. Relation between red blood cell distribution width and inflammatory biomarkers in a large cohort of unselected outpatients. Arch Pathol Lab Med. 2009;133:628-32.

8. Felker GM, Allen LA, Pocock SJ, Shaw LK, McMurray JJ, Pfeffer MA, et al. Red cell distribution width as a novel prognostic marker in heart failure: data from the CHARM program and the Duke databank. J Am Coll Cardiol. 2007;50:40-7

9. Tonelli M, Sacks F, Arnold M, Moye L, Davis B, Pfeffer M. The cholesterol and recurrent events (CARE) trial Investigators. Relation between red blood cell distribution width and cardiovascular event rate in people with coronary disease. Circulation. 2008:117:163-8.

10. Evans TC, Jehle D. The red blood cell distribution width. J Emerg Med. 1991; 9(Suppl 1):71-4

11. Patel KV, Ferrucci L, Ershler WB, Longo DL, Guralnik JM. Red blood cell distribution width and the risk of death in middle-aged and older adults. Arch Intern Med. 2009;169:515-23.

12. Allen LA, Felker GM, Mehra MR, Chiong JR, Dunlap SH, Ghali JK, et al. Validation and potential mechanisms of red cell distribution width as a prognostic marker in heart failure. J Card Fail. 2010;16:230-8.

13. Förhécz Z, Gombos T, Borgulya G, Pozsonyi Z, Prohászka Z, Jánoskuti L. Red cell distribution width in heart failure: prediction of clinical events and relationship with markers of ineffective erythropoiesis, inflammation, renal function, and nutritional state. Am Heart J. 2009;158:659-66.

14. Weiss G, Goodnough LT. Anemia of chronic disease. N Engl J Med. 2005; 352:1011-23.

15. Macdougall IC, Cooper A. The inflammatory response and epoetin sensitivity. Nephrol Dial Transplant. 2002;17(Suppl 1):48-52.

16. Levine B, Kalman J, Mayer L, Fillit HM, Packer M. Elevated circulating levels of tumor necrosis factor in severe chronic heart failure. N Engl J Med. 1990; 323:236-41

17. Hojo Y, Ikeda U, Katsuki T, Mizuno O, Fukazawa H, Kurosaki K, et al. Interleukin 6 expression in coronary circulation after coronary angioplasty as a risk factor for restenosis. Heart. 2000:84:83-7.

18. Agema WR, Jukema JW, Pimstone SN, Kastelein JJ. Genetic aspects of restenosis after percutaneous coronary interventions: towards more tailored therapy. Eur Heart J. 2001;22:2058-74.

19. Monraats PS, R P Agema W, Jukema JW. Genetic predictive factors in restenosis. Pathol Biol (Paris). 2004;52:186-95.

20. Lee MS, David EM, Makkar RR, Wilentz JR. Molecular and cellular basis of restenosis after percutaneous coronary intervention: the intertwining roles of platelets, leukocytes, and the coagulation-fibrinolysis system. J Pathol. 2004;203:861-70.

21. Kuwano T, Miura S, Shirai K, Ike A, Mori K, Shimizu T, et al. Serum levels of bilirubin as an independent predictor of coronary in-stent restenosis: a new look at an old molecule. J Atheroscler Thromb. 2011;18:574-83.

22. Nakagawa Y, Kimura T, Morimoto T, Nomura M, Saku K, Investigators j-C R, et al. Incidence and risk factors of late target lesion revascularization after sirolimus-eluting stent implantation (3-year follow-up of the j cypher registry). Am J Cardiol. 2010;106:329-36.

\section{Publisher's Note}

Springer Nature remains neutral with regard to jurisdictional claims in published maps and institutional affiliations.

Ready to submit your research? Choose BMC and benefit from:

- fast, convenient online submission

- thorough peer review by experienced researchers in your field

- rapid publication on acceptance

- support for research data, including large and complex data types

- gold Open Access which fosters wider collaboration and increased citations

- maximum visibility for your research: over $100 \mathrm{M}$ website views per year

At $\mathrm{BMC}$, research is always in progress.

Learn more biomedcentral.com/submission 